\title{
How Public R\&D Funding Can Be Profitable in Europe and in International Financial Markets?
}

https://doi.org/10.21272/fmir.2(4).13-19.2018

\section{Francesco Di Tommaso}

$\mathrm{PhD}$ Economics and Finance, University of Rome La Sapienza, Economics Faculty, Via del Castro Laurenziano, Rome, Italy

\begin{abstract}
I start to define that Public funding is the tool with which the State helps the production system make the necessary investments for the development of new products / services and for the improvement of the company performance.

Despite the existence of these funds, we must say that there is no finance law facilitated that provides coverage of the entire financial needs; this means that if you want to open a restaurant, a computer company, a company that produces mechanical components or a company that makes glass processing or any other business, you can not think that money puts them only the state in the form of contributions or loans; a part of the investment must also cover it with your money. This is something that we must specify because there are so many aspiring entrepreneurs (above all) that a little "claim" that the State or whoever takes over the entire entrepreneurial risk from the financial point of view: that is, they imagine that to put the money it must be someone else. But such an idea is contrary to the concept of business risk, which is (and remains) of the entrepreneur.
\end{abstract}

Keywords: Corporate Governance, Financial Markets.

JEL Classification: G0, G32.

(C) The Authors, 2018. This article is published with open access at Sumy State University.

Cite as: F. D. Tommaso. (2018). How Public R\&D Funding Can Be Profitable in Europe and in International Financial Markets? Financial Markets, Institutions and Risks, 2(4), 13-19. https://doi.org/10.21272/ fmir.2(4).13-19.2018

\section{How to Achieve in The Public Funds in Italy?}

In Italy depending on the type of contribution and the Region where you intend to start the activities, the amount of contributions and subsidized loans varies. If, for example, the estimated investment to open a business is 150,000 euros, government grants can range from $25-30 \%$ up to $50-60 \%$ of the entire investment depending on the place where you intend to start the business. Obviously, this disparity in the granting of contributions is directly dependent on the economic development conditions of the Region in which you have to make the investment: the more a region is developed from an economic point of view, the less are the contributions granted by the State and, on the contrary, the less the Region is developed and the contributions are greater.

So if you open an activity in Northern Italy (where the regions are more developed from an economic point of view) the contributions granted are around 20-30\%; this means that the State finances approximately 40,000 euros for the opening of the activity; the remaining $€ 110,000$ must be put to you by recourse or by your own money (the so-called own capital) or by borrowing from banks, other financial institutions or some other lender (even private). On the other hand, if you plan to open the business in Sardinia or in the Southern regions (less developed from an economic point of view) then the public contribution can cover up to $60-70 \%$ of the investment and then the State gets to grant contributions up to at 100,000 euros. And you have to put the remaining money on it.

So, if you intend to make use of public facilities you can access it only if you think you can make available part of the amount of the investment: the possibility of obtaining public funding, in this way, increase the use of these public incentives go to integrate the financial resources that you too must invest in your business idea. Please also note that these contributions, most of the time, are provided to S.A.L. (that is to STATE WORKING ADVANCEMENT) that is, in times following the moment in which you have made the investment. This is undoubtedly a limitation of these incentives because these long times contrast with the liquidity needs that the entrepreneur has to carry out his activity. 
To access these forms of facilitation you can contact these subjects: the State, the Regions, the Provinces, the Municipalities, the Chambers of Commerce, the European Union (through the Direct and Indirect European Funds). Depending on the law to which they refer, these facilities may relate to and support the development of particular sectors of the economy, or the development of specific entrepreneurial figures, or certain types of companies, or particular geographical.

\section{Public Funds: Empirical Analysis}

The phenomenon of subsidies is a phenomenon ancient and always widespread, not only in Italy, but in most states. Traditionally, the doctrine has examined this phenomenon in relation to its ability to manage economy. In fact, grants come used to encourage economic initiative private and direct it towards social welfare purposes: iaids are therefore a very important tool useful to control and, together, direct the initiative private economy, an instrument that is in a certain way alternative, but also complementary, to the authorizing measures.

The traditional doctrine that dealt with the phenomenon of subsidies, trying to identify their exact location in the entirety of the acts administrative authorities, has encountered numerous difficulties. The reasons for this difficulty, as evidenced by the same doctrine, are multiple and also derive from the fact that the same phenomenon is differently reconstructed a according to the different objectives that those have set themselves who analyzed it.

Some authors have considered that the difficulty of to legally frame the subsidies depended on from the lack of a unique terminology: the existence of various terms ("grant, contribution, means of financial aid, tools of incentive ... ") to indicate the same phenomenon has determined a substantial "equivocality of the language". Other authors have, however, considered that the lack of a univocal definition of the phenomenon derived from the fact that its economic importance is social make it easily identifiable even in absence of precise terminological indications, and that, of consequently, this phenomenon should be found in "every benefit that is granted by the state or other public legal person, or in public hands, and lead to the growth of a subject's assets stranger ", without having to reunite all the different ones case in a unique terminology. To this doctrine are opposed, however, those who have highlighted the importance of documenting the relief financial and social significance of this phenomenon, identifying it within a legal typology well determined. The financial importance of subsidies derives, in fact, both from the strong diffusion of aid measures and, consequently, from the strong impact on public spending of the same activity of incentive, both from the progressive increase of the use of these tools that has occurred during the course of the years and that was determined by them fungibility. The grant instruments, in fact, serve "to the state leadership of the economic initiative private "so much so that Pototschnig called it subsidy as "a means of guaranteeing the initiative private economy "and allow" directing and drive private economic initiative ". Through the of subsidies it is possible to succeed in addressing the economic initiative of individuals without recourse necessarily to coercive measures: by granting one subsidy, one is proposed to the private entrepreneur preferential choice for certain initiatives, those precisely encouraged, maintaining, however, unchanged its effective freedom of decision. In turn, however, precisely the power to direct the choices of individuals inherent in the instrument of the grant ha determined some differences of opinion, finding the doctrine divided between those who believed that it was an instrument for the management of the alternative economy al authoritative power, and how many, however, have highlighted the coercive factual value of the aid tool To access these forms of facilitation you can contact these subjects: the State, the Regions, the Provinces, the Municipalities, the Chambers of Commerce, the European Union (through the Direct and Indirect European Funds).

Depending on the law to which they refer, these facilities may relate to and support the development of particular sectors of the economy, or the development of specific entrepreneurial figures, or certain types of companies, or particular geographical areas.

To access these contributions and obtain public funding as a result, you must meet the requirements that are:

$>$ the size of the company: for each subsidy it is established whether the grants are granted to microenterprises, or to small businesses, medium-sized companies or large companies;

$>$ the location of the company: the amount and amount of subsidized loans also depends on the place where the company carries out its business; the laws of facilitated finance are addressed to the whole national territory but also and above all to geographical areas "depressed" and disadvantaged from an economic and social point of view. 
Frequently the laws of facilitated finance are aimed at the geographical areas defined as "Objective 1", which are the areas in which, in the last 3 years, a per capita GDP of less than $75 \%$ of the European average has been recorded. At the moment the Italian regions that fall within this Objective 1 are: Calabria, Basilicata, Puglia, Sicily, Sardinia and Molise (with a temporary aid scheme).

The companies operating in the "Objective 2" geographical areas, ie those areas in which there is a strong industrial decline marked by a high unemployment rate, can also benefit from government grants. Italian areas that fall within this Objective 2 are some areas of Abruzzo, Emilia Romagna, Friuli Venezia Giulia, Lazio, Liguria, Lombardy, Marche, Piedmont, Tuscany, Trentino Alto Adige, Umbria, Valle d'Aosta and Veneto); the sector of activity: facilities are provided for specific sectors of the economy such as crafts, commerce, tourism, research, agriculture, etc .; the social structure: some contributions are destined to certain subjects: young people, women, etc; the business plan (or business project) of support: it must be attached to the request for the contribution. It is the document in which the productive, organizational, marketing, financial and economic aspects of the company must be highlighted; the form of subsidization: contributions can be granted in the form of subsidized loans; of contribution in c / exercise; of contribution in c / capital; of facilitated mortgages; Eligible expenses: only expenses directly and exclusively related to the business project are eligible for contributions; the submission of the application: is subject to the opening of the national call, or regional, or provincial, or municipal. When submitting the application, it is necessary to respect the conditions for participation in the call for proposals which are territoriality, the size of the company, the economic sector, the company structure, the amount of available funds and eligible expenses; Public funding is certainly useful and convenient for entrepreneurs. However, we advise you to make a "correct" use and not consider them as your only source of financing because they have a limited duration and at the end of their payment, your company must still be able to self-sustain from an economic-financial point of view. to last over time. fulfill social security tasks - they were typical purposes of the "social state", the science of administrative law was formed in a context totally different social, that of the State of right, within which these tools do not they were considered of the same importance. Pericu highlighted that the non-communicability between science administrative law and the aid measures derived from the fact that the science of administrative law in the Rule of law is aimed at finding instruments suitable for get a balance between the two positions pposites of authority and freedom, and instead, in the performance activity does not highlight the moment authoritative of the State as opposed to positions of freedom of the citizen. Pericu observed as in cultural context of the rule of law, not there was still room to examine institutions that they seemed not to contain the possibility of affecting on individual freedom and private property and from this caused the impossibility to place such tools in the schemes developed within the framework of the rule of law; in reality, however, Pericu himself it then exceeded these historical-cultural limits, admitting that the social state did not pose itself in antithesis with the rule of law, but that it was necessary only find the right balance between these two forms of state organization.

In this research work and surpassing the uncertainties caused by the lack of a clear one terminological definition of the phenomenon, Pericu in primis and in its continuation the doctrine have however carried out, over the years, a thorough analysis of the phenomenon, trying to reach a qualification typological of the different manifestations of the activity of subsidy, to the identification of the position legal status of the holders of a claim to the grant of the grant itself and to a correct one framing of this instrument in its purpose of economic direction. And it is precisely the role of the economic direction of the various measures of subsidy what is most relevant to the moment current: this study, in fact, is directed to examine mainly this role, also in order to verify if it still exists and, therefore, if a speech with regard to aid measures can be said again current and useful.

As already seen, in fact, subsidies, agreements in their broadest sense, or as the granting of a benefit from a State or another public legal entity, or in the hand public administration, which leads to the growth of the patrimony of a foreign subject, constitute an instrument of management of the economy that has been widely used by the States and which has been growing over the years years; however, it is a practice that clashes with the prohibition of state aid enshrined in the European Treaty ed it is precisely because of this contrast that there is proposes to check whether there is still an interest legal action against this instrument of action.

What we want to ascertain is precisely if, in presence of this prohibition, and of the necessary finalization of the policies of the States with the objective unique to realize and maintain an economy of open market and free competition that derives from simple belonging to the European Union, either still a discourse on the phenomenon of the "Subsidies" on "state aid" and if this instrument economic planning still exists, and both 
feasible. The traditional doctrine that over the years has dealt with the phenomenon of subsidies it is collided with the lack of precise indications a regulatory level, but it managed anyway to elaborate a theory about it and rebuild it guidelines on which to identify the rules action. At the present time, however, the analysis principal is aimed at verifying whether it exists still some use to analyze the phenomenon of the provision of aid measures or if the speech it must be considered completely obsolete and devoid of any practical relevance. The doubt about the existence or not of a practical utility in an analysis of the phenomenon of grants at the present time stems from the fact that the States that want to put in place today a measure of help in order to entice in a certain direction the choices of the companies operating in their field geographic are faced with a twofold constraint: in primis the direct link, which derives from the prohibition of aid of State enshrined in Articles 87 et seq Treaty; secondly a different constraint, but equally incisive, which derives from the strong limits of budget which are imposed on States as a result of their membership of the European Union. Following the creation of the European Union the Market has taken on a priority role, too compared to the same States, and has become itself the main end, which conditions and limits policies national, which are no longer free, but must necessarily take place in accordance with the principle of an open and free market economy competition. Membership of the European Union, beyond impose on States a first limit, which derives directly from the prohibition of state aid, determines a further limit, which is in turn twofold and which consists of a double budget constraint. States for effect of belonging to the European Union are subject to a double budget constraint, which derives both from the creation of a monetary union, and from the necessary price parity.

Economic and monetary union, with the introduction of the fixed parity between the currencies introduced starting from 1 January 1999 and with the release of the euro from 1 January 2002, determined by the States members, the loss of their powers in this area monetary policy, to transfer them to the Community bodies. This has the impossibility for States to affect the currency balance, to solve some problems of the trade balance. Traditionally, in fact, the States could alternatively affect the scale commercial and foreign exchange and thus managed to remedy one's crises by making them fall back on the other against which directly acted; this was possible because the modification of one it can also have effects in the other: a strong one economic devaluation, for example, can produce significant economic benefits for production, in how much ends up facilitating exports and reducing them imports, and can, therefore, help reduce debt public. With the creation of the Economic Union e monetary, however, states have lost the chance to affect the currency balance and use the latter to increase the national economy where there is a moment of crisis.

To this first constraint on the intervention policy of the States another one is added, which conditions the exercise of the political power of states, and in reason of the existence of which it seems right to ask oneself if a speech on state aid is still current, such constraint is determined by the debt limit public, which is not explicitly enshrined in the Treaty but it is the consequence of the imperative limits in the management of the budget which are imposed on States by due to market protection.

The link between budgetary constraints and aid of State may not be immediate, and it is necessary, therefore, analyze the former, not so much on a theoretical level how much in their impact on reality, for understand to what extent they condition the same existence of aid.

The Member States of the European Union, though having remained theoretically free in the management of their budgets and in identifying the instruments of taxation and economic direction, dispose of, in reality, a very limited discretion, provided that it is tightened by strict restrictions on public debt total and annual indebtedness imposed from the European Union. The limits on public debt ed annual indebtedness respectively equal to $60 \%$ and $3 \%$ of GDP - put a double constraint on the political power of the individual States and, consequently, to the possibility for States to use the provision of aid as a form of economic direction: they limit it either directly or indirectly. They limit directly political power, placing a bond of budget, and limit it indirectly, because they pose a quantitative "ceiling" to sustainable global spending from each state, limit whose incidence is directly proportional to the incidence of public debt. If considers the level of average public indebtedness of States belonging to the European Community at current moment, it will be understood as the constraint of budget has such an impact on political power States to be doubted about the possibility of itself use the aid tool. This derives from the fact that if the public debt of a state exceeds $60 \%$ of GDP, or 3\% annual debt, it is not free to use their own resources: belonging in fact, the European Community requires him to do yes that debt and annual debt are maintained at below the pre-established limits, for which the State does not he will be able to use his own means freely but he will have to prioritization of resources in quantity necessary for the payment of interest on the accumulated debt, in order to prevent it from growing further, and only later, with any resources remained able to provide for the needs of the economy. 
It is evident, however, that since the resources available they are fixed, if they are needed to pay interest on excess debt and / or to limit debt, they will necessarily be subtracted from the needs of the States and, therefore, can not be used for stimulate production, to stimulate projects, to help companies in difficulty.

The budget constraints imposed by membership to the European Community therefore produce one compression of the political power of states to do to doubt that the instruments of intervention in the economy

they still exist. Every time the public debt is very high (or that it is the same, or even higher, at the limit of $60 \%$ - which happens at the moment current for the majority of Member States -) yes determines the disappearance of financial instruments necessary to exercise the power of direction economy.

While depriving the national political power of his main instruments of economic direction, i budgetary constraints imposed by the Community do not deprive the states of their discretion in weighting of the needs of the community, do not impose constraints resource allocation and leave individual states free to move their resources according to their own evaluations, choosing to address certain sectors economy rather than others; certainly you can not not to consider that, in fact, the budget constraints imposed by the Community make almost nothing discretion of States because they set a limit to the total volume of usable resources, a limit that has such an impact to leave to the States less resources than would be necessary for meet the basic needs of society.

In practice, the budget constraints imposed on States, despite being indirect constraints, they end up limiting the power to grant aid more than it does the prohibition expressly sanctioned by the Treaty: the

In fact, the Treaty prohibits the provision of one only specific type of aid, while budgetary constraints limit the entire power of state intervention economy. The Treaty prohibits the provision of only one specific type of aid: prohibits the provision of those State measures having a specific character and bring an economic advantage to a company, impacting trade between Member States. The prohibition State aid, as set out in Articles 87 et seq Treaty therefore prevents the grant exclusively those measures that respond to the predetermined characteristics that alter the competition, while the budget constraint prevents the provision of any aid measure, because determines the disappearance of the financial instrument, of the economic resources that are indispensable for implement any aid measure. It is precisely the existence of this double bond to the discretion of states that raise doubt if a speech on state aid can be considered still current: the Treaty has banned the disbursement of those measures that are incompatible with the protection of the Market, because they are capable of altering competition; budgetary constraints have affected discretion States to prevent the use of measures of help as tools for economic management, for lack of those resources that are indispensable for put in place an economic planning and for entice companies in a certain direction, so I ask whether the subsidies in reality can still be to exist.

This study presents itself precisely this objective: in the light of what was reconstructed by the doctrine about the concept of subsidy and in light of the limits sanctioned specifically by the Treaty - which prohibits aid incompatible with the protection of the market - and in general from membership in the European Community - in terms of budgetary constraints - it is necessary to verify whether the non-state have more discretion and, consequently, a speech on state aid is no longer relevant, for the impossibility of individual States to put in place one any economic and / or planning policy incentive, or if, instead, this analysis is still useful and current, and can serve to rebuild the spaces of residual discretion and, perhaps, to identify in how the delivery of aid measures can still be done constitute an instrument for the management of the economy of development.

\section{State Funds - Grants for public intervention in economics in the social sector}

The notion of "state aid" is not of easy and immediate definition, as it is not outlined by any normative source. It follows that while state aid can take innumerable and disparate forms, the only definition legislation from which the notion of "State aid" can be found in the description in Article 87 et seq. of the EC Treaty, which, however, reality, refers only to a part of them, that is only to state aid prohibited by legislation Community, because they are incompatible with the market common.

First of all, therefore, we must try to identify what "state aid" consists of: the meaning can be rebuilt through an analysis of the their forms of explanation, interventions, implemented and feasible, with regard to these measures and consequences related both to their institution and to the their suspension. to construct the characterizing elements of the measures of help, identify the interests related to them, understand what the positive and negative effects are they can be traced back. Such an analysis will allow reconstruct what the methods of intervention against the aid considered negative, ed together what are the reasons for which they 
are determined forms of aid should be considered useful and they should therefore be stimulated rather than prohibited. Secondly of all, it will be necessary to establish gods general criteria by which to identify those measures that can actually be called "aid" State "and clarify the scope and effects; you will have to, however, however, carry out an analysis on a case by case basis, in as, as claimed by much of the doctrine1, it can not be said "to exist a notion legal and objective aid ", but every measure can be defined as such only after an analysis carried out on a case-by-case basis and in concrete, on the basis of sufficiently certain and clearly applicable criteria, in how much they are founded on parameters, juridical and economic, objectives, which alone provide that certainty of a right that is indispensable in order to allow the public authorities and private operators to carry out conscious choices.

\section{The interests that flow into it}

The problematic nature of the state aid discipline derives from various and different reasons, among which the most important ones undoubtedly derive from the convergence of heterogeneous and often opposed interests into them. These interests can be identified essentially in four groups: the Community interest, aimed at the protection of the common market, the interest of the individual Member States, which grant aid, the interests of companies or associations of undertakings receiving aid and finally, the interest of the companies or associations of companies competing with the beneficiaries.

The intrinsic contrasts between the various "subjects" involved appear evident and immediately we perceive how the discipline on state aid sees two opposing policies clash: the liberal policies of the European Community, which looks with confidence to the Market, and those of the Member States, whereas, instead, they observe the market failures, which they would like to remedy precisely through the provision of aid to their companies, which directly suffer the "inefficiencies" of the market.

In addition to the aforementioned "policy contrast", there are contrasts between the various positions of the companies: on the one hand, the beneficiaries of the aid measures consider them legitimate and request their disbursement; on the other hand, the competing companies point to the intrinsic injustice present. in the aid itself and would demand its elimination. The former believe that the aid belongs to them, due to their disadvantaged situation, while the others believe that this measure, if granted, would cause distortions in the market and, above all, would alter the equilibrium of the market itself, creating inequalities rather than resolving them, and placing the companies that are not addressed to them in a disadvantaged situation compared to the beneficiary companies.

The composition of different interests and purposes that are part of the same notion of aid determines that the judgment on the compatibility or otherwise of each measure can not be formulated in relation to a single objective (such as, for example, the creation of the common market and / or of a perfect competition regime) but it must be carried out in relation to a set of objectives which, both individually and jointly considered, all contribute to determining the notion of common interest relevant for aid policy purposes.3. This is evident when the Commission, by granting the derogations, authorizes aid, which in itself would be incompatible, using the counterpart criterion, according to which "the distortions of competition caused by the aid are counterbalanced by the benefits received by the internal market as a whole "and, therefore, must still be accepted.

\section{The interest of the Communities}

The interest of the Community which is relevant in the field of State aid is in favor and protection of competition, given that "the main aim of competition policy is ... the realization of the single market, which is outlined as a primary interest of the Community in turn functional to the realization of other purposes".

The competition policy pursued by the European Community is therefore aimed at achieving a single European market, for which it is necessary for companies to find themselves in conditions that are as homogeneous as possible: that is why the Community interest goes to to oppose the payment of any form of State aid5, to the extent that the provision of such measures could alter the equilibrium and the rules of the market. Furthermore, the Community's opposition to aid measures is fully understandable if it reflects on the fact that, as has been observed by authoritative doctrines, "the customs union itself would collapse if the Member States could free themselves the balance of the market itself, creating inequalities rather than solving them, and placing the companies that do not they are addressees in a disadvantaged situation compared to beneficiary companies. The composition of interests and purposes different from the same notion of help determines that the judgment on the compatibility or not of each measure can not be formulated in relation to 
a single objective (such as, for example, implementation of the common market and / or a scheme of perfect competition) but must be carried out in relation to a set of objectives that are considered individually, be considered jointly, all they contribute to determine the notion of interest common relevance for aid policy.3. This becomes apparent when the Commission, granting exemptions, authorize aid, which in itself would be incompatible, using the criterion of counterpart, according to which "the distortions to competition caused by the aid are counterbalanced by benefits received by the internal market as a whole "and, therefore, must still be accepted.

\section{Conclusion}

In merit of my paper I can say that the subject-matter of public finance is not static, but dynamic which is continuously widening with the change in the concept of state and functions of the state. As the economic and social responsibilities of the state are increasing day by day, the methods and techniques of raising public income, public expenditure and public borrowings are also changing. In view of the changed circumstances, it has given more responsibilities in the social and economic field. In the other hand Public finance is a study of income and expenditure or receipt and payment of government. It deals the income raised through revenue and expenditure spend on the activities of the community and the terms 'finance' is money resource i.e. coins. But public is collected name for individual within an administrative territory and finance. On the other hand, it refers to income and expenditure. Thus public finance in this manner can be said the science of the income and expenditure of the government. In fact different economists have defined public finance differently. Some of the definitions are given below.

\section{Questions for reflection and discussion}

1 How the Public Fund they can be issued?

2 Which project cab be supported by public funds_ which mechanism do you consider is the most important?

3 Summarize the Public Funds problems in Europe. Do you think they are all of equal importance? If not, which Public Funds problem do you feel contributed the most to the social development?

4 To what extent do you think a Public Funds in Europe is likely to occur?

\section{References}

1. Basu, Kaushik. (1997). Analytical Development Economics: The Less Developed Economy Revisited, The MIT Press.

2. Bird, Graham. (2004). International Finance and the Developing Economies, Palgrave Macmillan.

3. Bell, Crive. (2003), Development Policy as Public Finance, Oxford University Press.

4. Gale, Douglas. (1994). The Efficient Design of Public Debt, in Franklin Allen and D. Gale, Financial Innovation and Risk Sharing, The MIT Press.

5. Gibson, Heather D. (1996). International Finance: Exchange Rates and Financial Flaws in the International System, Longman.

6. International Finance, Eun, Resnick and Sabherwal. (2004). Wall Street Journal Aril 9, 1996.

7. Krugman, Paul. (1988). Financing vs. Forgiving a Debt Overhang, Journal of Development Economics, 29, 253-268, North Holland.

8. Sachs, Jeffrey. (1989). The Debt Overhang of Developing Countries, in Guillermo Calvo, Ronald Findlay, Pentti Kouri and Jorge Braga de Macedo (eds.), Debt, Stabilization and Development: Essays in Memory of Carlos Diaz-Alejandro, Blackwell.

9. Bird, Graham. (1995). IMF Lending to Developing Countries: Issues and Evidence, Routledge.

10. Boldo, Michael D. and Christopher M. Meissner (2005). The Role of Foreign Currency Debt in Financial Crises: 1880-1913 vs. 1972-1997," NBER Working Paper Series No. 11897, National Bureau of Economic Research, Cambridge: MA.

11. Kindleberger, Charles P. (2005). Manias, Panic and Crashes - A History of Financial Crises (5th Edition), John Wiley \& Sons, Inc.

12. Polackova, Hana (1998). Government Contingent Liabilities: A Hidden Risk to Fiscal Stability, World Bank Policy Research Working Paper, The World Bank. 